DOI: $\underline{10.20472 / T E .2017 .5 .2 .001 ~}$

\title{
THE CULTURAL GAP IN EFL SECONDARY STAGE CURRICULA AND INSTRUCTIONAL PRACTICES AS PERCEIVED BY SAUDI STUDENTS', TEACHERS' AND SUPERVISORS
}

\author{
RUBA BATAINEH, ALI EID RESHIDI
}

\begin{abstract}
:
This study examines 284 Saudi students', 81 teachers' and 27 supervisors' perceptions of the cultural gap in EFL secondary stage curricula and instructional practices, using a three-version questionnaire, whose validity and reliability were appropriately established. The findings revealed that the respondents are keen on creating a balanced cultural mix through the presentation of examples from the two (sets of) cultures. The findings did not reveal any statistically significant differences in the respondents' perceptions which can be attributed to gender. However, statistically significant differences, which can be attributed to position, were found in the perceptions of the cultural gap between Arab and English cultures.
\end{abstract}

\section{Keywords:}

cultural gap; curriculum; instructional practices; perceptions, Saudi Arabia

JEL Classification: 129

\section{Authors:}

RUBA BATAINEH, Yarmouk University, Jordan, Email: rubab@yu.edu.jo

ALI EID RESHIDI, Saudi Ministry of Education, Saudi Arabia, Email: Honest1424@hotmail.com

\section{Citation:}

RUBA BATAINEH, ALI EID RESHIDI (2017). The cultural gap in EFL secondary stage curricula and instructional practices as perceived by Saudi students', teachers' and supervisors. International Journal of Teaching and Education, Vol. V(2), pp. 1-21., 10.20472/TE.2017.5.2.001 


\section{Introduction and Background}

There is an evident relationship between language and culture (Kramsch, 1993), as language supersedes communication of letters and sounds. By definition, culture is a mixture of different codes covering the way of life, tradition, rituals, beliefs, values, morals, shared customs and all the habits that are practiced by a particular community using a particular language as a means of expression (Al-Jabbari, Sadeq \& Azmi, 2011).

No two cultures are identical, especially within societies that are distinctly different from one another, like those of Eastern and Western communities. Every society has its own cultural features which affect language and, hence, people's communication with the world around them (Al-Jabbari et al, 2011; Bataineh, 2005).

In the context of teaching English as a foreign language (EFL), language is the most important aspect of culture (Geertz, 1973). In fact, scholars (e.g., Harumi, 2002; Eoyang, 2003; Janzen, 2008; Tochon, 2009) claim that foreign language learning is intimately related to culture learning so much so that the two have come to be seen as indivisible entities. Thus, given this close interdependence between language and culture, it goes without saying that a significant part of the mission of EFL education should be allowing students to understand the language and nuances of its culture (Fageeh, 2011). Therefore, regardless of the instructional approach the teacher adopts, he/she should enhance students' cultural awareness as a catalyst for foreign language teaching and learning (Bataineh, 2005).

The role of English in the Kingdom of Saudi Arabia is as important as it is in any other developing country. Innovative technology, the Internet and the spread of social networks (e.g., Facebook, Twitter) have resulted in a major transition in foreign language education.

Like English, Arabic is a source of pride for those who speak it, as it is the language of Holy Quran. The Kingdom of Saudi Arabia, where the current study is conducted, has never been colonized, which is why it has always been referred to as a country with one language (Liton, 2012). Furthermore, The Kingdom of Saudi Arabia enforces Islamic regulations in every aspect of life, which may have caused a cultural gap between the Saudi culture (viz., behaviors, customs, habits and way of life) and other Western cultures (Shah, Afsar, Haq \& Khan, 2012). However, being the lingua franca of the world today, English cannot be ignored, and Saudi authorities are keen on developing English learning and teaching.

As language and culture interact with each other, cultural gaps may be inevitable. This is bound to cause misinterpretation and misunderstanding between language learners and speakers of the target language (TL). Even though culture overlap may exist between any two language communities, the degree of this overlap depends on the degree of contact between the two communities and the extent to which they are related (Lyons, 1981).

\section{Problem, Purpose and Questions of the Study}

Through the researchers' collective experience as EFL practitioners in Saudi Arabia, they share in the conviction that teaching the cultural competence must go hand in hand with teaching the linguistic competence, but certainly not at the expense of the learner's own cultural identity or in a manner which clashes with the fabric of the native culture (in this case, Saudi and Islamic cultures). Saudi EFL learners, across grade levels, aspire to speak English fluently, but most of them find English too challenging to master for a number of reasons, such 
as interference from the mother tongue, lack of opportunities to use English in their daily lives, and traditional English instruction.

Since all the EFL textbooks taught in Saudi Arabian schools are authored by Saudis (sometimes in collaboration with foreign experts), very little 'Anglo-American' culture is represented in these textbooks (both for the primary and secondary stages). EFL teachers need to be made aware of this fact and look for means to counteract misconceptions students are likely to develop, leading to a cultural gap in the Saudi foreign language classroom.

Thus, the study aims to examine the perceptions of Saudi EFL secondary stage students, teachers and supervisors of the cultural gap between Arab and English cultures in secondary stage curricula and instructional practices. It further aims to explore the potential effect of the variables of position and gender on these respondents' perceptions.

More specifically, the study attempts to answer the following questions:

1. What are the perceptions of Saudi EFL students, teachers and supervisors of the cultural gap(s) between Arab and English cultures in secondary stage curricula and instructional practices?

2. Are there statistically significant differences (at $\alpha=0.05$ ) in the respondents' perceptions of the cultural gap between Arab and English cultures, which can be attributed to the variables of position and gender?

\section{Significance and Limitations of the Study}

This study derives its significance from its scope, as it examines the perceptions of the cultural gap between the Arab and English cultures. Its significance may also be derived from its novelty. To the researchers' best knowledge, this topic has not been investigated within pretertiary education in Saudi Arabia, and, thus, the study is expected to make a valuable contribution to the literature on the Saudi EFL context.

Nonetheless, the study is limited to EFL students, teachers and supervisors in Ha'il District, Saudi Arabia. Furthermore, an added potential limitation is brought about by the fact that only a questionnaire was used to collect the data. The use of other instruments (e.g., classroom observation, interview, content analysis) would have added more depth to the findings.

\section{Review of Related Research}

A plethora of studies (e.g, Aliakbari, 2005; Dalbani, 2002; Lee, 2009; Bataineh, 2005; Bataineh, Qublan \& Bataineh, 2016) have examined the issue of culture in EFL textbooks. Dalbani (2002) examined both the cultural gap in EFL textbooks and teachers' perceptions of the inclusion of the Arab culture in those textbooks. She viewed the supremacy of culture over language in EFL textbooks as a colonial issue and objected to the focus on both the foreign language and culture in the textbook. She $(2004$, p.5) maintained that

we want to learn about the foreign language and we want to learn about the foreign culture because in so doing we will become better citizens of the global world, but still we want others to recognize our own cultural identity in the same way that we recognize theirs. 
She reported that EFL textbooks promote foreign culture and that teachers have moderately positive perceptions of the Western culture as represented in the EFL textbooks used in Arab countries.

Similarly, Aliakbari (2005) analyzed the presentation of culture in Iranian foreign language education in general and high school EFL education in particular. He found that the textbooks were superficial in their treatment of culture and, thus, inadequate for the task of teaching culture-specific skills in the deeper sense (e.g., norms, values, belief) or culture-general skills (e.g., intercultural communication and understanding).

Bataineh (2005) examined the representation of the local environment, operationally defined as the Jordanian habitat, heritage sites, geography, climate, daily life, landscape, social setting and (Arab and Moslem) cultural heritage, in tenth grade EFL textbooks. Through a holistic qualitative analysis of how the local environment is represented in the textbooks, she found that the Jordanian environment is moderately represented and, thus, recommended that more information about the Jordanian culture be added to the textbooks.

Lee (2009) studied how eleven South Korean high school EFL textbooks teach, depict, and deal with culture. He reported a complete avoidance of the Korean culture both in the textbooks and instructional practices. He concluded that American and British cultural aspects prevailed over the cultural aspects of the Korean home culture.

Asgari (2011) examined the cultural values in EFL textbooks and their influence on Iranian students and, by extension, on the Iranian community. She reported some cultural values, but she claimed that they had no influence on either the learners or the community.

Lappalainen (2011) investigated the potential domination of the American culture in Finnish EFL textbooks. Using content-analysis and a list of criteria, she reported a substantial cultural bias in the textbooks for the benefit of the Finnish culture. She found that the Finnish culture overrode any other Western culture which was almost completely ignored in the textbooks under study.

Kim (2012) reported that South Korean EFL textbooks were socially and culturally-biased against the South Korean culture in favor of the authors' country (mainly the US and the UK). Kim also reported a trend towards male supremacy and a depiction of women as submissive housewives.

Forman (2014) observed teachers' practices to alleviate the cultural gaps in Tai EFL textbooks. The textbooks were found in accordance with the social values dominant in the Thai society. However, they were found misleading in their cultural and lexical accuracy, which caused teachers to doubt the content of these textbooks and, thus, resist using them.

Bataineh, Qublan and Bataineh (2016) examined the cultural aspects in Total English textbook taught in English service courses in several Jordanian universities and instructors' and students' perceptions about the inclusion of aspects of the Arab culture in the textbooks. They reported that the textbook was loaded with Western thought, has some seemingly colonial purposes, and lacked for references to any Islamic and/or Arab cultural aspects. 
Most of the research reviewed investigated the cultural aspects in EFL textbooks. Some biased cultural representations and cultural gaps between the native and target language cultures were reported (e.g., Bataineh, Qublan \& Bataineh, 2016; Lee, 2009). Most studies showed that the native culture is almost always neglected in EFL textbooks in favor of the target cultures (e.g., Kim, 2012; Lee, 2009). However, some textbooks, such as those in Thailand and Finland, were found representative of their native cultures (e.g., Forman, 2014; Lappalainen, 2011).

This study comes as a continuation of the line of research on cultural content in textbooks, especially that on Arab and Islamic culture (e.g., Bataineh, 2005; Bataineh, Qublan \& Bataineh, 2016) and its potential inclusion in EFL textbooks. The current study aims to corroborate previous findings by reporting on the perception of three major stakeholders in the language teaching process (viz., the students, teachers and supervisors) of the cultural gap in Saudi EFL textbooks and instructional practices.

\section{Sample and Instrumentation}

Three populations have been targeted: all 14,825 male and 11,136 female secondary school students, 1,396 teachers of English, and 27 supervisors in Ha'il, Saudi Arabia, in the first semester of the academic year 2014/2015. Three hundred and ninety seven questionnaires were distributed, but only 381 were returned, indicating a response rate of $95.97 \%$.

The sample of the study consisted of three sub-samples: students, teachers, and supervisors. The initial sample consisted of 300 male and female students who were randomly selected from the population of the study. However, sixteen subjects were excluded because they did not return the questionnaires, reducing the subsample of students to 284 . The sample also included 81 school teachers and 16 supervisors of English. Teachers and supervisors were chosen purposefully through the second researcher's work as a supervisor. Table 1 presents the distribution of the sample according to the variables of gender and position.

\section{Table 1: Sample Distribution}

\begin{tabular}{lllll}
\hline \multirow{2}{*}{ Position } & & \multicolumn{2}{l}{ Gender } & Total \\
\cline { 3 - 4 } Teacher & $\mathrm{n}$ & Male & Female & \\
& $\%$ & 53 & 28 & 81 \\
Student & $\mathrm{n}$ & 65.4 & 34.6 & 100 \\
& $\%$ & 113 & 171 & 284 \\
Supervisor & $\mathrm{n}$ & 39.8 & 60.2 & 100 \\
& $\%$ & 11 & 5 & 16 \\
Total & $\mathrm{n}$ & 68.8 & 31.3 & 100 \\
& $\%$ & 177 & 204 & 381 \\
\cline { 2 - 4 } & & 46.5 & 53.5 & 100
\end{tabular}


To achieve the purposes of the research, a three-version, five-point Likert scale (viz., very important, important, fairly important, hardly important, and not important) questionnaire was designed, a version for each of the three sub-samples. The first version was distributed to the students, the second to the teachers, and the third to the supervisors. Each of the three versions consisted of four domains: aims of teaching culture (6 items), cultural aspects in the language classroom (10 items), textbooks (4 items), and teacher practices (7 items).

To establish validity, the three versions of the questionnaire were submitted for review to a jury of six Jordanian professors. The jury's comments were taken into consideration per the academic norms. The questionnaire was originally written in English, but it was translated into Arabic to make it easier for the students to respond without the risk of the potential language barrier. The translation was also validated by a jury of three experts whose concerns were also taken into account in producing the final version of the questionnaire.

To establish reliability, the three versions of the questionnaire were piloted on a sample of 47 subjects: 27 students, 15 teachers and 5 supervisors, who were excluded from the main sample. A test-retest was administered to the three sub-samples with a two-week interval. Using Cronbach Alpha, the internal consistency of the questionnaire was 0.88 while the retest application that checked the reliability of the questionnaire was 0.79 , a result deemed appropriate for the purpose of the study.

\section{Findings and Discussion}

The findings of the first research question are presented for the three sub-samples along the four domains of the questionnaire and then discussed before moving onto the second question, which is done in the same manner.

\section{Findings and Discussion of the First Research Question}

To answer the first research question, which examines the perceptions of Saudi students, teachers and supervisors of the cultural gap between Arab and English cultures in secondary stage curricula and instructional practices, means and standard deviations were calculated for each of the three sub-samples along the four domains of the questionnaire: the aims of teaching cultural content, focus on cultural aspects, textbooks, and teacher practices. Table 2 presents the means and standard deviations for the first domain. 
Table 2: Means and Standard Deviations of the Students' Perceptions of the Aims of Teaching Cultural Content

No. Item

Mean

SD

1 Learning how to be tolerant of others

4.34

1.01

2 Understanding one's personal and national culture

4.33

0.97

3 Learning how to use the rules of etiquette when

4.22

0.67

4 Learning facts about English-speaking countries (e.g., USA, UK)

5 Developing critical attitudes towards society

6 Understanding the value systems of other cultures

3.54

1.08

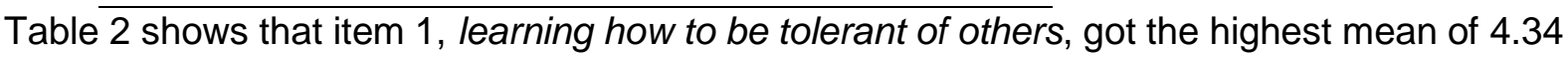
with a standard deviation of 1.01 , followed by item 2, understanding one's personal and national culture, and item 3, learning how to use the rules of etiquette when travelling abroad, with means of 4.33 and 4.22 and standard deviations of 0.97 and 1.12, respectively. On the other hand, item 6 , understanding the value systems of other cultures, scored the lowest mean of 3.54 with a standard deviation of 1.08 , followed by item 5 , developing critical attitudes towards society, and item 4, learning facts about English-speaking countries (e.g., USA, UK), with means of 3.56 and 3.79 and standard deviations of 1.12 and 1.12, respectively.

Table 3 presents the means and standard deviations of the students' responses to the second domain, focus on cultural aspects.

Table 3: Means and Standard Deviations of the Students' Perceptions on the Domain of Focus on Cultural Aspects

No. Item

Mean SD

\begin{tabular}{lllr}
\hline 7 & Understanding the political systems of other cultures & 3.57 & 1.19 \\
8 & Knowing the religious beliefs of other cultures & 3.53 & 1.33 \\
9 & Highlighting the history of other cultures & 3.40 & 1.06 \\
10 & Highlighting relationship patterns among the young & 3.38 & 1.25 \\
11 & Understanding parenting and raising styles within foreign cultures & 3.35 & 1.30 \\
12 & Knowing about the national and religious holidays of other cultures & 3.30 & 1.34 \\
13 & Understanding the customs and traditions of other cultures & 3.26 & 1.03 \\
14 & Knowing about the art (e.g., literature, films) within cultures & 3.19 & 1.28 \\
15 & Knowing about family relationships within foreign cultures & 3.12 & 1.22 \\
16 & Identifying minorities within the cultures & 3.07 & 1.07
\end{tabular}


Table 3 shows that item 7, understanding the political systems of other cultures, got the highest mean of 3.57 with a standard deviation of 1.19 followed by item 8 , knowing the religious beliefs of other cultures, and item 9 , highlighting the history of other cultures, with means of 3.53 and 3.40 and standard deviations of 1.33 and 1.06, respectively. However, item 16 , identifying minorities within the cultures, scored the lowest mean of 3.07 with a standard deviation of 1.07 , followed by items 15 , knowing about family relationships within foreign cultures, and 14, knowing about the art (e.g., literature, films) within cultures, with means of 3.12 and a standard deviations of 1.28 and 1.22 , respectively.

Table 4 presents the means and standard deviations of the students' responses to the third domain, textbooks.

Table 4: Means and Standard Deviations of the Students' Perceptions of the Textbooks Domain

No. Item Mean SD

17 Helping increase mutual understanding and respect among people $4.15 \quad 1.01$ from different cultures

18 Promoting Arab and Islamic culture in general and Saudi culture in $4.02 \quad 1.00$ particular

19 Including some aspects of the target language culture as part of the $\begin{array}{ll}3.53 & 1.08\end{array}$ classroom teaching

20 Promoting foreign cultures with reference to ethnicity, origin, and $3.24 \quad 1.08$ occupation

Table 4 shows that item 17, helping increase mutual understanding and respect among people from different cultures, and item 18, promoting Arab and Islamic culture in general and Saudi culture in particular, got the highest means of 4.15 and 4.02 with standard deviations of 1.01 and 1.00 , respectively. However, items 20 , promoting foreign cultures with reference to ethnicity, origin, and occupation, and item 19, including some aspects of the target language culture as part of the classroom teaching, scored the lowest means with 3.24 and 3.53 with standard deviations of 1.08 and 1.08 , respectively.

Table 5 presents the means and standard deviations of the students' responses to the fourth domain, teacher practices.

Table 5: Means and Standard Deviations of the Students' Perceptions of Teacher Practices

No. Item

Mean SD

2 Provide contrastive cultural examples (e.g., 'In Arabic, we say ahlan wa

$3.93 \quad 1.06$ sahlaln where in English we say nice to meet you) when meeting someone for the first time

2 Modify his/her teaching styles in light of his/her knowledge of the $3.91 \quad 1.14$ students' culture 
2 Show differences between the Arab and foreign cultures (e.g., greetings, use of first/last names, giving/responding to compliments) in the classroom

2 Present real-life cultural content (e.g., food, people, housing, clothes).

2 Include cultural content focusing on values, beliefs and attitudes of the foreign culture

2 Include cultural content in well-planned activities

2 Present some cultural information about his/her native country along with the target language culture in class

Table 5 shows that item 21, providing contrastive cultural examples (e.g., in Arabic, we say ahlan wa sahlaln where in English we say Nice to meet you) when meeting someone for the first time, got the highest mean of 3.93 with a standard deviation of 1.06 , followed by item 22 , modifying the teacher's teaching styles in light of his/her knowledge of the students' culture, and item 23, showing differences between the Arab and foreign cultures (e.g., greetings, use of first/last names, giving/responding to compliments) in the classroom, with means of 3.91 and 3.82 and standard deviations of 1.14 and 1.13, respectively. However, item 27, presenting some cultural information about his/her native country along with the target language culture in class, scored the lowest mean of 3.65 with a standard deviation of 1.08 , followed by item 26 , including cultural content focusing on values, beliefs and attitudes of the foreign culture, and item 25, including cultural content in well-planned activities, that scored the means of 3.66 and 3.66 with standard deviations of 1.04 and 0.99 , respectively.

Table 6 presents the means and standard deviations of the teachers' responses to the first domain, the aims of teaching cultural content.

\section{Table 6: Means and Standard Deviations of the Teachers' Perceptions of the Aims of} Teaching Cultural Content

\begin{tabular}{llll} 
No. & Item & Mean & SD \\
\hline 1 & Learning how to use the rules of etiquette when travelling abroad & 4.00 & 1.10 \\
2 & Learning how to be tolerant of others & 3.91 & 1.12 \\
3 & Learning facts about English-speaking countries (e.g., USA, UK) & 3.78 & 1.07 \\
4 & Understanding one's personal and national culture & 3.68 & 1.09 \\
5 & Understanding the value systems of other cultures & 3.53 & 0.96 \\
6 & Developing critical attitudes towards society & 3.47 & 1.05
\end{tabular}

Table 6 shows that item 1, learning how to use the rules of etiquette when travelling abroad, got the highest mean of 4.00 with a standard deviation of 1.01 , followed by item 2 , learning 
how to be tolerant of others, and item 3, learning facts about English-speaking countries (e.g., USA, UK), with means of 3.91 and 3.78 and standard deviations of 1.12 and 1.07 , respectively. However, item 6, developing critical attitudes towards society, scored the lowest mean of 3.47 with a standard deviation of 1.05 , followed by item 5 , understanding the value systems of other cultures, and item 4, understanding one's personal and national culture, with means of 3.53 and 3.68 and standard deviations of 0.96 and 1.09 , respectively.

Table 7 presents the means and standard deviations of the teachers' responses to the second domain, focus on cultural aspects.

Table 7: Means and Standard Deviations of the Teachers' Perceptions of Focus on Cultural Aspects

\begin{tabular}{llll} 
No. & Item & Mean & SD \\
\hline 7 & Understanding parenting and raising styles within foreign cultures & 3.58 & 1.13 \\
8 & Understanding the customs and traditions of other cultures & 3.33 & 1.06 \\
9 & Knowing the religious beliefs of other cultures & 3.31 & 1.01 \\
10 & Highlighting relationship patterns among the young & 3.30 & 1.07 \\
11 & Highlighting the history of other cultures & 3.17 & 1.19 \\
12 & $\quad$ Understanding the political systems of other cultures & 3.16 & 1.07 \\
13 & $\quad$ Identifying minorities within the cultures & 3.01 & 0.97 \\
14 & $\quad$ Knowing about the national and religious holidays of other cultures & 2.96 & 1.16 \\
15 & Knowing about the art (e.g., literature, films) within cultures & 2.95 & 1.24 \\
16 & $\quad$ Knowing about family relationships within foreign cultures & 2.94 & 1.11
\end{tabular}

Table 7 shows that item 7, understanding parenting and raising styles within foreign cultures, got the highest mean of 3.58 with a standard deviation of 1.13 , followed by item 8 , understanding the customs and traditions of other cultures, and item 9 , knowing the religious beliefs of other cultures, with means of 3.33 and 3.31 and standard deviations of 1.06 and 1.01 , respectively. On the other hand, item 16, knowing about family relationships within foreign cultures, scored the lowest mean of 2.94 with a standard deviation of 1.11 , followed by item 15, knowing about the art (e.g., literature, films) within cultures, with a mean of 2.95 and a standard deviation of 1.24 and by item 14, knowing about the national and religious holidays of other cultures, with a mean of 2.96 and a standard deviation of 1.18 .

Table 8 presents the means and standard deviations of the teachers' responses to the third domain, textbooks. 
Table 8: Means and Standard Deviations of the Teachers' Perceptions on the Textbooks Domain

No. Item

Mean SD

$17 \quad$ Promoting Arab and Islamic culture in general and Saudi culture in $4.15 \quad 0.98$ particular

18 Helping increase mutual understanding and respect among people $4.00 \quad 1.14$ from different cultures

19 Promoting foreign cultures with reference to ethnicity, origin, and $3.40 \quad 1.35$ occupation

20 Including some aspects of the target language culture as part of the $\begin{array}{lll}3.28 & 1.23\end{array}$ classroom teaching

Table 8 shows that item 17, promoting Arab and Islamic culture in general and Saudi culture in particular, and item 18, helping increase mutual understanding and respect among people from different cultures, got the highest means of 4.15 and 4.00 with standard deviations of 0.98 and 1.14 , respectively. However, items 20 , including some aspects of the target language culture as part of the classroom teaching, and item 19, promoting foreign cultures with reference to ethnicity, origin, and occupation, scored the lowest means with 3.28 and 3.40 with standard deviations of 1.23 and 1.35 , respectively.

Table 9 presents the means and standard deviations of the teachers' responses to the fourth domain, teacher practices.

Table 9: Means and Standard Deviations of the Teachers' Perceptions of Teacher Practices

No. Item

Mean SD

\begin{tabular}{llllllll}
\hline 21 & Show differences between the Arab and foreign cultures (e.g., 3.84 & 0.97
\end{tabular} greetings, use of first/last names, giving/responding to compliments) in the classroom

22 Provide contrastive cultural examples (e.g., In Arabic, we say ahlan wa sahlaln where in English we say nice to meet you) when meeting someone for the first time

23 Present real-life cultural content (e.g., food, people, housing, clothes)

24 Present some cultural information about his/her native country along 3.49 with the target language culture in class

25 Modify his/her teaching styles in light of his/her knowledge of the students' culture

26 Include cultural content in well-planned activities

27 Include cultural content focusing on values, beliefs and attitudes of the foreign culture 
Table 9 shows that item 21, showing differences between the Arab and foreign cultures (e.g., greetings, use of first/last names, giving/responding to compliments) in the classroom, got the highest mean of 3.84 with a standard deviation of 0.97 , followed by item 22 , providing contrastive cultural examples (e.g., In Arabic, we say ahlan wa sahlaln where in English we say nice to meet you) when meeting someone for the first time, and item 23 , presenting reallife cultural content (e.g., food, people, housing, and clothes), with means of 3.80 and 3.73 and standard deviations of 1.08 and 0.97 , respectively. However, item 27, including cultural content focusing on values, beliefs and attitudes of the foreign culture, scored the lowest mean of 3.19 with a standard deviation of 1.13 , followed by item 26 , including cultural content in wellplanned activities, and item 25, modifying his/her teaching styles in light of his/her knowledge of the students' culture, which scored the means of 3.32 and 3.37 with standard deviations of 0.97 and 1.17 , respectively.

Table 10 presents the means and standard deviations of the supervisors' responses to the first domain, the aims of teaching cultural content.

Table 10: Means and Standard Deviations of the Supervisors' Perceptions of the Aims of Teaching Cultural Content
No. Item
Mean SD
$1 \quad$ Learning how to use the rules of etiquette when travelling abroad

$4.25 \quad 0.68$
2 Learning how to be tolerant of others
$4.19 \quad 0.66$
3 Understanding one's personal and national culture
$4.06 \quad 1.00$
4 Learning facts about English-speaking countries such as USA, and
Great Britai
$3.81 \quad 0.83$
5 Understanding the value systems of other cultures
$3.63 \quad 0.81$
6 Developing critical attitudes towards society
$3.56 \quad 0.81$

Table 10 shows that item 1, learning how to use the rules of etiquette when travelling abroad, got the highest mean of 4.25 with a standard deviation of 0.68 , followed by item 2 , learning how to be tolerant of others, and item 3, understanding one's personal and national culture, with means of 4.19 and 4.06 and standard deviations of 0.66 and 1.00 , respectively. However, item 6, developing critical attitudes towards society, scored the lowest mean of 3.56 with a standard deviation of 0.81 , followed by item 5 , understanding the value systems of other cultures, and item 4, learning facts about English-speaking countries (e.g., USA, UK), with means of 3.63 and 3.81 and standard deviations of 0.81 and 0.83 , respectively.

Table 11 presents the means and standard deviations of the supervisors' responses to the second domain, focus on cultural aspects. 
Table 11: Means and Standard Deviations of the Supervisors' Perceptions of Focus on Cultural Aspects

No. Item

Mean SD

\begin{tabular}{llll}
\hline 7 & Understanding parenting and raising styles within foreign cultures & 3.75 & 0.77 \\
8 & Highlighting relationship patterns among the young & 3.50 & 0.52 \\
9 & Understanding the customs and traditions of other cultures & 3.19 & 0.54 \\
10 & Identifying minorities within the cultures & 3.19 & 0.66 \\
11 & Highlighting the history of other cultures & 3.06 & 0.77 \\
12 & Knowing the religious beliefs of other cultures & 3.06 & 0.77 \\
13 & Understanding the political systems of other cultures & 3.06 & 0.77 \\
14 & Knowing about the art (e.g., literature, films) within cultures & 2.44 & 1.03 \\
15 & Knowing about family relationships within foreign cultures & 2.31 & 1.01 \\
16 & Knowing about the national and religious holidays of other cultures & 2.31 & 1.01
\end{tabular}

Table 11 shows that the item 7 , understanding parenting and raising styles within foreign cultures, got the highest mean of 3.75 with a standard deviation of 0.77 , followed by item 8 , highlighting relationship patterns among the young, and item 9, knowing the religious beliefs of other cultures, with means of 3.50 and 3.19 and standard deviations of 0.52 and 0.66 , respectively. However, item 16, knowing about the national and religious holidays of other cultures, scored the lowest mean of 2.31 with a standard deviation of 1.01 , followed by item 15 , knowing about family relationships within foreign cultures, with a mean of 2.31 and a standard deviation of 1.01, and then followed by item 14, knowing about the art (e.g., literature, films) within cultures, with a mean of 2.44 and a standard deviation of 1.03 .

Table 12 presents the means and standard deviations of the supervisors' responses to the third domain, textbooks.

Table12: Means and Standard Deviations of the Supervisors' Perceptions of the Textbooks Domain

No Item Mean SD

17 Promoting Arab and Islamic culture in general and Saudi culture in $4.81 \quad 0.40$ particular

18 Helping increase mutual understanding and respect among people from $4.50 \quad 0.52$ different cultures

19 Promoting foreign cultures with reference to ethnicity, origin, and $3.19 \quad 1.05$ occupation 
20 Including some aspects of the target language culture as part of the $\begin{array}{lll}3.06 & 0.93\end{array}$ classroom teaching

Table 12 shows that item 17, promoting Arab and Islamic culture in general and Saudi culture in particular, and item 18, helping increase mutual understanding and respect among people from different cultures, got the highest means of 4.81 and 4.50 with standard deviations of 0.40 and 0.52 , respectively. However, items 20 , including some aspects of the target language culture as part of the classroom teaching, and item 19, promoting foreign cultures with reference to ethnicity, origin, and occupation, scored the lowest means of 3.06 and 3.19 and standard deviations of 0.93 and 1.05 , respectively.

Table 13 presents the means and standard deviations of the supervisors' responses to the fourth domain, teacher practices.

Table 13: Means and Standard Deviations of the Supervisors' Perceptions of Teacher Practices

No. Item

Mean SD

$21 \quad$ Provide contrastive cultural examples (e.g., In Arabic, we say ahlan wa sahlaln where in English we say nice to meet you) when meeting $4.06 \quad 0.25$ someone for the first time)

22 Show differences between the Arab and foreign cultures (e.g., 4.060 .25 greetings, use of first/last names, giving/responding to compliments) in the classroom

23 Present some cultural information about his/her native country along $\begin{array}{lll}3.81 & 0.40\end{array}$ with the target language culture in class

24 Present real-life cultural content (e.g., food, people, housing, clothes) $3.75 \quad 0.58$

25 Modify his/her teaching styles in light of his/her knowledge of the $\begin{array}{lll}3.13 & 0.72\end{array}$ students' culture

26 Include cultural content in well-planned activities $\quad 3.06 \quad 0.85$

27 Include cultural content focusing on values, beliefs and attitudes of the $2.81 \quad 0.91$ foreign culture

Table 13 shows that both item 21, providing contrastive cultural examples (e.g., In Arabic, we say ahlan wa sahlaln where in English we say nice to meet you) when meeting someone for the first time, and item 22, showing differences between the Arab and foreign cultures (e.g., greetings, use of first/last names, giving/responding to compliments) in the classroom, got the highest means of 4.06 with a standard deviation of 0.25 , followed by item 23 , presenting some cultural information about his/her native country along with the target language culture in class, with a mean of 3.81 and a standard deviation of 0.40 . On the other hand, item 27, including cultural content focusing on values, beliefs and attitudes of the foreign culture, scored the lowest mean of 2.81 with a standard deviation of 0.91 , followed by item 26 , including cultural content in well-planned activities, and item 25, modifying his/her teaching styles in light of his/her knowledge of the students' culture, which got the means of 3.06 and 3.13 and standard deviations of 0.85 and 0.72 , respectively. 
The findings of the first question, which asks about the perceptions of Saudi students, teachers, and supervisors of the cultural gap, suggest that some major cultural differences are perceived to exist between Arab and English cultures. As for the aims of teaching the cultural content, most responses showed very positive attitudes towards understanding and mingling with people from Western cultures and a strong desire to communicate with 'the other'. For instance, the majority of the respondents across the three sub-samples expressed a desire to learn not only about the rules of etiquette but also about how to be tolerant of others.

In terms of the focus on cultural aspects, the respondents expressed willingness to know more about the cultural aspects of the Western culture, suggesting empathy for the foreign culture. For instance, a large number of the respondents expressed their desire to understand parenting and raising styles in foreign cultures.

The vast majority of respondents' perceptions about the textbooks were balanced and hardly biased towards their native Saudi and Islamic culture. There were few concerns about promoting the Arabic and Islamic culture in general, especially among teachers who seemed to support intermingling between the two cultures.

The religious nature of the Saudi society appeared to influence the respondents' perceptions. However, Saudi students were reportedly highly influenced by social media which encourage openness as opposed to the conservativeness and adherence to norms valued in their community, which may have been responsible for creating a cultural gap between the home and target cultures.

Teachers' and supervisors' perceptions were not different from those of students. All three sample groups seemed to appreciate the differences between cultures and, at the same time, not to mind adopting qualities which do not clash with their native culture. Students' perceptions also showed how they adhere to their ideology, which they derive from their parents and society. They focused on the aspects of mutual respect rather than promoting foreign cultures.

After examining the respondents' responses concerning their awareness of the cultural gap in curricula and instructional practices, comparisons were made to pinpoint the indicators of intercultural awareness. These observations were found consistent with the trends reported in the literature, as previous research (see, for example, Aliakbari, 2005; Al-Jabbari, 2011; Bataineh, 2005; Bataineh, Qublan \& Bataineh, 2016; Lee, 2009) reports that textbooks and other instructional materials slant more towards the target culture than the native culture.

\section{Findings and Discussion of the Second Research Question}

To answer the second question, which addresses whether or not there are statistically significant differences (at $\alpha=0.05$ ) which can be attributed to the variables of position and gender, the means and standard deviations of the perceptions of Saudi students, teachers and supervisors of the cultural gap between Arab and English cultures in secondary stage curricula and instructional practices were calculated, as shown in Table 14. 
Table 14: Means and Standard Deviations of Students', Teachers' and Supervisors' Perceptions per Position and gender

\begin{tabular}{llll} 
Variable & Level & Mean & SD. \\
\hline Position & Teacher & 3.47 & 0.57 \\
& Student & 3.64 & 0.54 \\
& Supervisor & 3.47 & 0.39 \\
Gender & Male & 3.56 & 0.55 \\
& Female & 3.63 & 0.54 \\
\hline
\end{tabular}

Table 14 shows observed statistical differences (at $\alpha=0.05$ ) among the Saudi students', teachers' and supervisors' perceptions of the cultural gap between Arab and English cultures in secondary stage curricula and instructional practices, which can be attributed to position and gender. To establish whether or not these differences are statistically significant, two way ANOVA is used, as shown in Table 15.

Table 15: Two-way ANOVA of Saudi Students', Teachers' and Supervisors' Perceptions of the Cultural Gap per Position and gender

\begin{tabular}{llllll} 
Source & Sum of Squares & Df & Mean Square & $F$ & Sig. \\
\hline Position & 1.843 & 2 & 0.921 & 3.167 & 0.043 \\
Gender & 0.086 & 1 & 0.086 & 0.295 & 0.587 \\
Error & 109.658 & 377 & 0.291 & & \\
Total & 111.885 & 380 & & &
\end{tabular}

Table 15 shows no statistically significant differences (at $\alpha=0.05$ ) among Saudi students', teachers' and supervisors' perceptions of the cultural gap between Arab and English cultures in secondary stage curricula and instructional practices, which can be attributed to gender. However, statistically significant differences (at $\alpha=0.05$ ) are evident among the Saudi students', teachers' and supervisors' perceptions the cultural gap between Arab and English cultures, which can be attributed to position.

Because the variables of the study are multi-level, Scheffe-Test was used for domain comparisons to determine whose benefits were the observed differences (at $\alpha=0.05$ ) among Saudi students', teachers' and supervisors' perceptions of the cultural gap in Saudi curricula and instructional practices, as shown in Table 16. 
Table 16: Scheffe-Test Results for the Saudi Students', Teachers' and Supervisors' Perceptions of the Cultural Gap by Position

\begin{tabular}{lllll} 
Position & & Supervisor & Teacher & Student \\
\hline Scheffe & Mean & 3.47 & 3.47 & 3.64 \\
\hline Supervisor & 3.47 & & & \\
Teacher & 3.47 & $0.00^{*}$ & \\
Student & 3.64 & 0.17 & 0.17
\end{tabular}

Table 16 shows statistically significant differences (at $\alpha=0.05$ ) among Saudi students', teachers' and supervisors' perceptions of the cultural gap between Arab and English cultures, which can be attributed to position, in favor of the student sub-sample.

Furthermore, means and standard deviations of the domains of Saudi students', teachers' and supervisors' perceptions of the cultural gap between Arab and English cultures in secondary stage curricula and instructional practices were calculated against the variables of position and gender, as shown in Table 17.

Table 17: Means and Standard Deviations of Saudi Students', Teachers' and Supervisors' Perceptions of the Cultural Gap by Position and Gender

Scale domains

\begin{tabular}{|c|c|c|c|c|c|c|}
\hline & & \multirow[b]{2}{*}{ Statistic } & \multirow{2}{*}{\multicolumn{2}{|c|}{$\begin{array}{ll}\text { Aims of } & \text { Focus on } \\
\text { Teaching } & \text { Cultural } \\
\text { Cultural } & \text { Aspects } \\
\text { Content } & \end{array}$}} & \multirow[b]{2}{*}{ Textbooks } & \multirow[b]{2}{*}{$\begin{array}{l}\text { Teacher } \\
\text { Practices }\end{array}$} \\
\hline & & & & & & \\
\hline \multirow[t]{6}{*}{ Position } & Teacher & Mean & 3.73 & 3.17 & 3.71 & 3.53 \\
\hline & & SD & 0.76 & 0.70 & 0.74 & 0.69 \\
\hline & Student & Mean & 3.96 & 3.32 & 3.74 & 3.77 \\
\hline & & SD & 0.67 & 0.69 & 0.66 & 0.67 \\
\hline & Supervisor & Mean & 3.92 & 2.99 & 3.89 & 3.53 \\
\hline & & SD & 0.59 & 0.62 & 0.49 & 0.38 \\
\hline \multirow[t]{4}{*}{ Gender } & Male & Mean & 3.93 & 3.20 & 3.73 & 3.67 \\
\hline & & SD & 0.70 & 0.75 & 0.64 & 0.66 \\
\hline & Female & Mean & 3.89 & 3.34 & 3.74 & 3.75 \\
\hline & & SD & 0.69 & 0.64 & 0.69 & 0.68 \\
\hline
\end{tabular}

Table 17 shows observed statistical differences among Saudi students', teachers' and supervisors' perceptions of the cultural gap between Arab and English cultures in secondary 
stage curricula and instructional practices, which can be attributed to the difference in the variable levels.

To verify the observed statistical differences, correlation coefficients were calculated among the respondents' perceptions of the cultural gap by using Bartlett-Test, as shown in Table 18.

Table 18: Bartlett-Test of Saudi Students', Teachers' and Supervisors' Perceptions of the Cultural Gap according to Position and Gender

\begin{tabular}{llll}
\hline & Aims & of & Focus on \\
Correlation & Teaching & Cultural & \\
& Cultural Textbooks & Aspects & \\
& Content & & \\
& & & \\
& & & \\
\hline
\end{tabular}

Focus on Cultural Aspects $\quad 0.48$

$\begin{array}{lll}\text { Textbooks } & 0.43 & 0.42\end{array}$

$\begin{array}{llll}\text { Teacher Practices } & 0.50 & 0.51 & 0.53\end{array}$

Bartlett's Test of Sphericity

\begin{tabular}{llcc}
\hline Likelihood Ratio & Approx. $X^{2}$ & Df & Sig. \\
\hline 0.000 & 414.064 & 9 & $0.00^{*}$
\end{tabular}

Table 18 shows a statistically significant relationship (at $\alpha=0.05$ ) among Saudi students', teachers' and supervisors' perceptions of the cultural gap between Arab and English cultures in secondary stage curricula and instructional practices, which can be attributed to position and gender

To identify which domain of the perceptions of Saudi students, teachers and supervisors of the cultural gap was influenced by the variables of position and gender, the variance contrast analysis was conducted on the respondents' perceptions along the two variables, as shown in Table 19.

Table 19: The Variance Contrast Analysis Results for Saudi Students', Teachers' and Supervisors' Perceptions of the Cultural Gap according to Position and Gender

\begin{tabular}{lllllll}
\hline \multirow{2}{*}{ Source } & Dependent Variable & $\begin{array}{l}\text { Sum of } \\
\text { Squares }\end{array}$ & Df & $\begin{array}{l}\text { Mean } \\
\text { Square }\end{array}$ & F & Sig. \\
\hline Position & Aims of Teaching Cultural Content & 3.893 & 2 & 1.946 & 4.130 & $0.017^{*}$ \\
& Focus on Cultural Aspects & 1.916 & 2 & 0.958 & 1.999 & 0.137 \\
& Textbooks & 0.453 & 2 & 0.226 & 0.504 & 0.605 \\
& Teacher Practices & 3.654 & 2 & 1.827 & 4.131 & $0.017^{*}$ \\
\hline \multirow{2}{*}{ Gender } & Aims of Teaching Cultural Content & 0.554 & 1 & 0.554 & 1.176 & 0.279 \\
& Focus on Cultural Aspects & 1.032 & 1 & 1.032 & 2.153 & 0.143 \\
& Textbooks & 0.006 & 1 & 0.006 & 0.013 & 0.911 \\
& Teacher Practices & 0.075 & 1 & 0.075 & 0.170 & 0.680 \\
\hline \multirow{2}{*}{ Error } & Aims of Teaching Cultural Content & 177.681 & 377 & 0.471 & & \\
& Focus on Cultural Aspects & 180.722 & 377 & 0.479 & & \\
& Textbooks & 169.489 & 377 & 0.450 & & \\
& Teacher Practices & 166.726 & 377 & 0.442 & & \\
\hline
\end{tabular}


Total

\begin{tabular}{lll} 
Aims of Teaching Cultural Content & 181.688 & 380 \\
Focus on Cultural Aspects & 184.430 & 380 \\
Textbooks & 169.947 & 380 \\
Teacher Practices & 170.914 & 380 \\
\hline
\end{tabular}

Table 19 shows statistically significant differences (at $\alpha=0.05)$ among the means of the two domains, aims of teaching cultural content and teacher practices, of the Saudi students', teachers' and supervisors' perceptions of the cultural gap which can be attributed to position. Scheffe-Test was conducted for multi-domains comparisons to investigate the significant differences (at $\alpha=0.05$ ) among the means of the two domains, aims of teaching cultural content, teacher practices, of the respondents' perceptions of the cultural gap according to position, as shown in Table 20.

Table 20: Scheffe-Test Results of multi-Domains comparisons for the Domains of Aims of Teaching Cultural Content and Teacher Practices due to Position

\begin{tabular}{|c|c|c|c|c|c|}
\hline \multirow{5}{*}{$\begin{array}{l}\text { Aims } \\
\text { of } \\
\text { Teaching } \\
\text { Cultural } \\
\text { Content }\end{array}$} & \multicolumn{2}{|l|}{ Position } & \multirow{2}{*}{$\begin{array}{l}\text { Teacher } \\
3.73\end{array}$} & \multirow{2}{*}{$\begin{array}{l}\text { Supervisor } \\
3.92\end{array}$} & \multirow{2}{*}{$\begin{array}{l}\text { Student } \\
3.96\end{array}$} \\
\hline & Scheffe & Mean & & & \\
\hline & Teacher & 3.73 & & & \\
\hline & Supervisor & 3.92 & 0.19 & & \\
\hline & Student & 3.96 & 0.23 & 0.05 & \\
\hline \multirow{5}{*}{$\begin{array}{l}\text { Teacher } \\
\text { Practices }\end{array}$} & Position & & Supervisor & Teacher & Student \\
\hline & Scheffe & Mean & 3.53 & 3.53 & 3.77 \\
\hline & Supervisor & 3.53 & & & \\
\hline & Teacher & 3.53 & 0.01 & & \\
\hline & Student & 3.77 & 0.24 & 0.24 & \\
\hline
\end{tabular}

Table 20 shows a statistically significant difference (at $\alpha=0.05)$ among the means for the two domains of aims of teaching cultural content and teacher practices among the Saudi students', teachers' and supervisors' perceptions, which can be attributed to position, in favor of students.

While gender was found to cause no statistically significant differences in the perceptions of Saudi students, teachers and supervisors of the cultural gaps between Arab and English cultures, position was found to cause significant statistical differences in favor of students. Both male and female respondents across the three sub-samples shared, more or less, the same perceptions of the cultural gaps, but students differed significantly from the other two subsamples.

\section{Conclusions, Pedagogical Implications and Recommendation}

As culture is defined as the composite pattern of, among other things, human thought, communication, language, practices, manners of interacting and roles amongst a social group and the ability to transmit these to the following generations (Goode, Sockalingam, Bronheim, 
Brown \& Jones, 2000), it is imperative that EFL learners, and other stakeholders, not only be aware of the intricate relationship between language and culture but also be able to put this awareness to use in learning the foreign language.

It is somewhat heartening to find that both male and female Saudi students are more aware of the cultural gaps in Saudi Arabian curricula and instructional practices (than their teachers and supervisors). Not only is this consistent with previous claims (see, for example, Fageeh, 2011) that teaching English cannot be isolated from teaching its culture, but it is also in sync with claims that cultural awareness is a significant contributor to English teaching and learning and a significant pedagogical means of raising motivation for learning the culture of English.

Based on the findings, EFL textbook authors, both local and foreign, are recommended to include content that potentially broadens students' horizons and fosters tolerance away from extremism and close-mindedness. As Saudi teachers and supervisors are a major source of trustworthy information, attitudes and skills, they should shoulder the responsibility of enlightening students about the significance of cultural tolerance and accepting others.

It is also recommended that Saudi students be taught how cultures co-exist with one another. The researchers also urge other researchers to conduct further research on the issue of cultural gap to raise students', teachers', and supervisors' respective awareness of this vital topic.

It is also recommended that this research be extended to other Saudi Arabian districts beside Ha'il to better portray perceptions concerning the cultural gap. Furthermore, content analyses may be used to identify potential cultural bias in Saudi EFL textbooks, not to mention using more data sources, such as classroom observations and interviews, to supplement the questionnaire used in this study.

\section{References}

Aliakbari, M. (2005). The Place of Culture in the Iranian ELT Textbooks in High School Level. Journal of Pan-Pacific Association of Applied linguistics, 9(1), 163-179.

Al-Jabbari, E., Sadeq, A. \& Azmi, J. (2011). Cultural Gaps in Linguistic Communication with Reference to English and Arabic Language Communities. Zarqa Journal for Research and Studies in Humanities, 11(1), 60-64.

Asgari, A. (2011). The Compatibility of Cultural Value in Iranian EFL Textbooks. Journal of Language Teaching and Research, 2(4), 887-894. https://doi.org/10.4304/jtr.2.4.887-894

Bataineh, R.F., Qublan, E.K. \& Bataineh, R.F. (2016). The Compatibility of Total English with the Arab Islamic Culture as Revealed by Content Analysis and Jordanian EFL Instructors' and Students' Views. International Journal of Language and Applied Linguistics, 2(2), 19-43.

Bataineh, R. (2005). The Representation of the Local Environment in Jordanian Tenth Grade English Textbooks. Association of Arab Universities Journal for Education and Psychology, 3(2), 1143.

Dalbani, H. (2002). Bridging the Cultural Gap in EFL Materials. Damascus University Journal for the Arts and Humanities, 20(1), 19-35. 
Eoyang, E. (2003). Teaching English as Culture: Paradigm Shifts in Postcolonial Discourse. Diogenes, 50(2), 3-16. https://doi.org/10.1177/0392192103050002001

Fageeh, A. (2011). At Crossroads of EFL Learning and Culture: How to Enhance Cross-cultural Awareness in EFL College Students at AU. Cross-Cultural Communication, 7 (1), 62-72. Retrieved 20 May 2015 from http://www.cscanada.net/index.php/ccc/ article/viewFile/1016/1035

Forman, R. (2014). How Local Teachers Respond to the Culture and Language of a Global English as a Foreign Language Textbook. Language, Culture \& Curriculum, 27 (1), 72-88. https://doi.org/10.1080/07908318.2013.868473

Geertz, C. (1973). The Interpretation of Cultures. New York: Basic Books.

Goode, T., Sockalingam, S., Bronheim, S., Brown, M. \& Jones, W. (2000). A Planner's Guide ... Infusing Principles, Content and Themes Related to Cultural and Linguistic Competence into Meetings and Conferences. National Center for Cultural Competence, Georgetown University Child Development Center, Center for Child Health and Mental Health Policy, University Affiliated Program. Retrieved 20 May 2015 from http://nccc.georgetown.edu/ documents/Planners Guide.pdf

Harumi, I. (2002). A New Framework of Culture Teaching for Teaching English as a Global Language. RELC Journal, 33(2), 36-57. https://doi.org/10.1177/003368820203300202

Janzen, J. (2008). Teaching English Language Learners in the Content Areas. Review of Educational Research, 78(2), 1010-1038. https://doi.org/10.3102/0034654308325580

Kim, H. (2012). Social and Cultural Issues in Some EFL Textbooks in Korea. Hawaii Pacific University TESOL Working Paper Series, 10, 30-39.

Kramsch, C. (1993). Context and Culture in Language Teaching. Oxford: Oxford University Press.

Lappalainen, T. (2011). Presentation of the American Culture in EFL Textbooks: An Analysis of the Cultural Content of Finnish EFL Textbooks for Secondary and Upper Secondary Education. Unpublished Master's Thesis. University of Jyväskylä, Finland. Retrieved 1 June 2014 from https://jyx.jyu.fi/dspace/handle/ 123456789/26866

Lee, Y. (2009). Treating Culture: What 11 High School EFL Conversation Textbooks in South Korea Do. English Teaching: Practice and Critique, 8(1), 76-96.

Liton, H. (2012). Developing EFL Teaching and Learning Practices in Saudi Colleges. International Journal of Instruction, 5(2), 129-152.

Lyons, J. (1981). Language and Linguistics. Cambridge: Cambridge University Press.

Shah, S., Afsar, A., Haq, H., \& Khan, Z. (2012). Course Contents of English Language Textbooks and their Relevance to Learners' Culture in an Islamic Context. Journal of Education and Practice, 3(12), 165-180.

Tochon, F. (2009). The Key to Global Understanding: World Languages Education—Why Schools Need to Adapt. Review of Educational Research, 79(2), 650 - 681. https://doi.org/10.3102/0034654308325898 